LA-UR- $96-2902$

Title:

Author(s)

Submitted to:

18th International Conference on Free Electron Lasers

Rome, Italy, 8/25-30/96
Richard L. Sheffield

John C. Goldstein

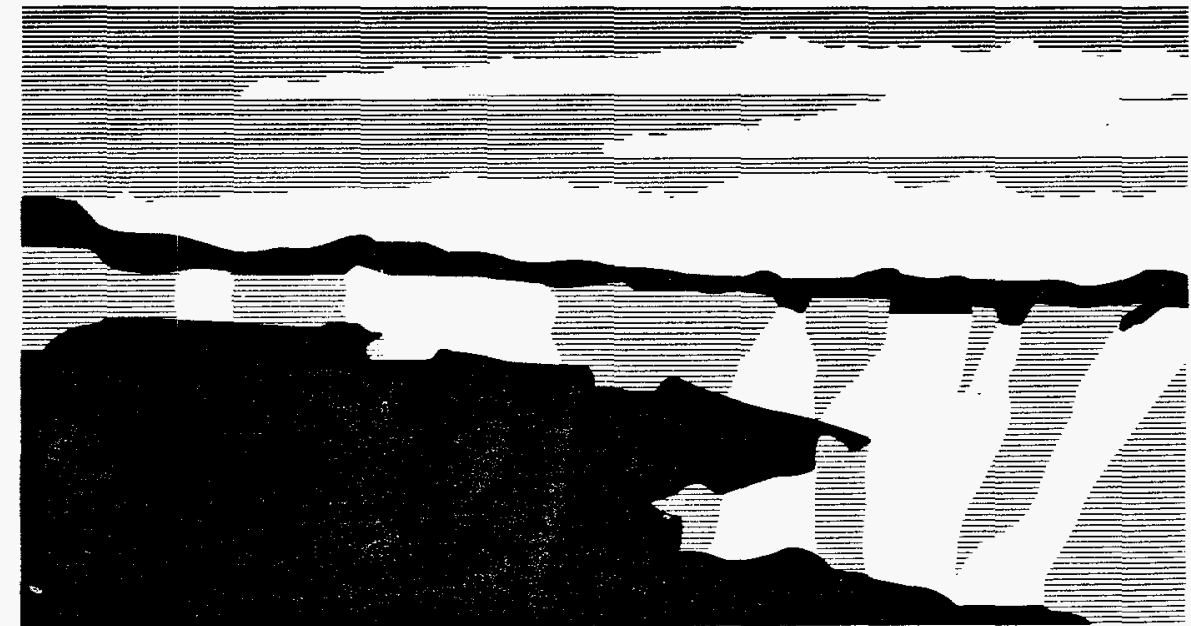

Los Alamos National Laboratory, an affirmative action/equal opportunity empldyer, is operated by the University of California for the U.S. Department of Energy under contract W-7405-ENG-36. By acceptance of this article, the publisher recognizes that the U.S. Government retains a nonexclusive, royalty-free license to publish or reproduce the published form of this contribution, or to allow others to do so, for U.S. Government purposes. The Los Alamos National Laboratory requests that the publisher identify this article as work performed under the auspices of the U.S. Department of Energy. 


\section{DISCLAIMER}

This report was prepared as an account of work sponsored by an agency of the United States Government. Neither the United States Government nor any agency thereof, nor any of their employees, makes any warranty, express or implied, or assumes any legal liability or responsibility for the accuracy, completeness, or usefulness of any information, apparatus, product, or process disclosed, or represents that its use would not infringe privately owned rights. Reference herein to any specific commercial product, process, or service by trade name, trademark, manufacturer, or otherwise does not necessarily constitute or imply its endorsement, recommendation, or favoring by the United States Government or any agency thereof. The views and opinions of authors expressed herein do not necessarily state or reflect those of the United States Government or any agency thereof. 


\section{DISCLAIMER}

Portions of this document may be illegible in electronic image products. Images are produced from the best available original document. 


\title{
Theoretical Study of the Design and Performance of a High-Gain, High-Extraction-Efficiency FEL Oscillator ${ }^{*}$
}

\author{
John C. Goldstein**, Dinh C. Nguyen, and Richard L. Sheffield \\ University of California \\ Los Alamos National Laboratory \\ Los Alamos, NM 87545
}

\begin{abstract}
We present the results of theoretical and simulation studies of the design and performance of a new type of FEL oscillator. This device, known by the acronym RAFELfor Regenerative_Amplifier Eree-Electron Laser, will be constructed in the space presently occupied by the AFEL (Advanced FEL) at Los Alamos, and will be driven by an upgraded (to higher average power) version of the present AFEL linac. In order to achieve a long-time-averaged optical output power of $\sim 1 \mathrm{~kW}$ using an electron beam with an average power of $\sim 20 \mathrm{~kW}$, a rather high extraction efficiency $\eta \sim 5 \%$ is required. We have designed a $2-\mathrm{m}-$ long undulator to attain this goal: the first meter is untapered and provides high gain while the second meter is linearly-tapered in magnetic field amplitude to provide high extraction efficiency in the standard K-M-R manner. Two-plane focusing and linear polarization of the undulator are assumed. Electron-beam properties from PARMELA simulations of the AFEL accelerator were used in the design. A large saturated gain, 500, requires a very small optical feedback to keep the device operating at steady-state. However, the large gain leads to distorted optical modes which require two- and three-dimensional simulations to adequately treat diffraction effects. This FEL will be driven by $17 \mathrm{MeV}$ electrons and will operate in the $16 \mu \mathrm{m}$ spectral region.
\end{abstract}

\section{Introduction}

A high average power laser has long been an unfulfilled promise of free-electron laser (FEL) technology. Power levels quoted in design studies during the SDI program in the United States were not achieved by factors exceeding one million. Thus, much more modest power levels, $\sim 1 \mathrm{~kW}$, are being sought by several different FEL research groups [1-3]. Los Alamos has recently started a program to build an FEL of this power level which is based on a rather novel design: a combination of high-gain and high-extraction-efficiency.

*This work was conducted under the auspices of the U. S. Department of Energy, supported (in part) by funds provided by the University of California for the conduct of discretionary research by Los Alamos National Laboratory.

**Corresponding author: Group XPA, MS B259, Los Alamos National Laboratory, Los Alamos, New Mexico 87545 USA; (505)-665-7725 (fax); (505)-667-7281 (tel); jcg@lanl.gov (e-mail). 
$-$

A high-gain device has several advantages: the turn-on time can be a very small fraction of the duration of a macropulse, and a large saturated gain means that only a very small fraction of the extracted power needs to be fed back into the wiggler to maintain steady-state operation. In fact, the saturated gain of the RAFEL is so large that the device is better described as a regenerative amplifier than a conventional FEL oscillator.

A large saturated gain implies an even larger small-signal gain. Large gains are known to lead to optical modes which are significantly distorted from ideal empty-cavity Gaussian modes. Hence, optical diffraction effects are very important, and doubly so for our design due to the features of our optical cavity. In this paper, we shall describe the current design of the RAFEL and its performance as predicted by two- and threedimensional simulations. The RAFEL is a very significant departure from previous Los Alamos FELs and therefore presents entirely new modeling and experimental challenges.

\section{RAFEL Design and Constraints.}

The design of the RAFEL was considerably influenced by a number of constraints as well as desired performance objectives. In order to achieve a time-averaged optical output power of $\sim 1 \mathrm{~kW}$, the high-brightness linac which presently drives the AFEL at Los Alamos [4] will be upgraded to produce a $17 \mathrm{MeV}$ electron beam with an average power of $\sim 20 \mathrm{~kW}$ [5]. This accelerator has been well characterized and compared with results of PARMELA simulations, and below we use the results of such simulations (in a different parameter regime from past work) as design parameters for the electron beam which will drive the RAFEL. Hence, an overall net FEL efficiency of $\sim 5 \%$ will be needed with this electron beam to reach the desired optical power level: in order to allow for various deviations from ideal conditions, a tapered undulator with a theoretical extraction efficiency of $\sim 10 \%$ was designed. In order to reduce the circulating power in the optical cavity, which in turn reduces the loading of the optical elements, a high-gain device was chosen with the goal of generating an output of $\sim 1 \mathrm{GW}$ from an input of $\sim 1 \mathrm{MW}$. The AFEL was built as a demonstration of a compact 
FEL, so the laboratory space available for a wiggler is limited to 2 meters. Simulations showed that, for the magnet properties chosen, a 1-m uniform undulator would provide high gain and bunching of the electron beam, while the desired extraction efficiency could be provided by another meter length of tapered undulator. The precise form of the tapering, that is, the axial ( $\mathrm{z}$ ) variation of the wiggler field amplitude $\mathrm{B}_{\mathrm{W}}$, is given in Eqs. (1) and (2) below:

$$
\begin{gathered}
\mathrm{B}_{\mathrm{W}}(\mathrm{z})=\mathrm{B}_{\mathrm{W}_{0}} \text { for } 0 \leq \mathrm{z} \leq \mathrm{z}_{0} \\
\mathrm{~B}_{\mathrm{W}}(\mathrm{z})=\mathrm{B}_{\mathrm{W}_{0}}\left(1-\alpha\left(\mathrm{z} / \mathrm{L}_{\mathrm{W}}\right)\right) \text { for } \mathrm{z}_{0}<\mathrm{z} \leq \mathrm{L}_{\mathrm{W}}
\end{gathered}
$$

For the RAFEL system, $\mathrm{B}_{\mathrm{W} 0}=0.7 \mathrm{~T}, \mathrm{z}_{0}=1 \mathrm{~m}, \mathrm{~L}_{\mathrm{W}}=2 \mathrm{~m}$, and the taper parameter $\alpha=0.6975$. The wiggler will be tapered in field amplitude rather than wavelength $\left(\lambda_{\mathrm{W}}=2 \mathrm{~cm}\right.$ is constant) in order to allow for as large a gap as possible: this is needed to accomodate the optical mode, as discussed below. We note that calculations have shown that $\sim 1.8 \mathrm{~m}$ of uniform undulator is needed to reach saturation if the device is started from spontaneous emission only (SASE operation), and that one cannot achieve the desired $10 \%$ extraction efficiency from the remaining $0.2 \mathrm{~m}$ of undulator. In addition, SASE saturates with a large optical bandwidth, and this optical field may not be useful to drive a tapered undulator [6]. Hence, the RAFEL is designed with an optical feedback system which supplies a narrow-bandwidth optical signal of sufficiently large power that only $\sim 1 \mathrm{~m}$ of uniform undulator is needed. Table 1 presents the e-beam and wiggler parameters on which the performance simulations are based. Further details of the wiggler design, including the novel scheme for producing two-plane focusing, can be found in [7]. A schematic of the entire system is shown in Figure (1).

\section{Optical Performance.}

\subsection{Single-wavefront amplifier performance.}

The wiggler was designed primarily by single-wavefront (that is, single frequency, or $\mathrm{CW}$ ) amplifier simula- 
tions. For the parameters listed in Table 1 , the maxmum small-signal gain $\mathrm{G}_{S S}$ is very large: $\mathrm{G}_{\mathrm{SS}}=8.09 \times 10^{6}$ at an optical wavelength of $15.8 \mu \mathrm{m}$. The theoretical 1-D gain length (power e-folding distance) for the parameters of the uniform wiggler part of the device [8] is $\left(2 \mathrm{k}_{\mathrm{W}} \rho \sqrt{3}\right)^{-1}=4.29 \mathrm{~cm}$, but the conditions for the validity of the $1-\mathrm{D}$ gain length [8] are not quite satisfied. Here, $\mathrm{k}_{\mathrm{W}}$ is the wiggler wavenumber and $\rho$, the high-gain FEL scaling parameter [8], has the value of $\rho=0.021416$ in the uniform wiggler part of the RAFEL device. The numerically calculated minimum gain length is about $7.0 \mathrm{~cm}$. The small-signal gain bandwidth is $\Delta \lambda=0.6 \mu \mathrm{m}$. The large signal ( $0.27 \mathrm{MW}$ injected power at the wiggler entrance) behavior peaks at a wavelength of $16.4 \mu \mathrm{m}$ where the gain is 2114 (571 MW output power) and the extraction efficiency is $10.86 \%$. We used $16.4 \mu \mathrm{m}$ in most of the $\mathrm{CW}$ design simulations because the small-signal gain, $5.608 \times 10^{6}$, is quite adequate at this wavelength.

The amplifier simulations revealed an optical mode structure which introduces an effect which is not yet treated correctly in the numerical calculations. While the transverse width of the optical mode is quite narrow in the untapered part of the RAFEL wiggler, the width increases rapidly in the tapered part of the undulator, particularly at small-signal conditions as illustrated in Figs. (2) and (3). We do not yet have a numerical model which properly treats reflections (at large angles of incidence) of the light from the walls of the wiggler itself, or from a beam tube which is inserted into the wiggler bore to prevent the generation of wakefields and the subsequent degradation of the electron beam quality. Hence, in our simulations, the transverse grid inside the wiggler on which the calculations are done is unphysically large; apertures are put at the wiggler entrance and exit which attempt to correct for the effects of a finite bore. In the RAFEL, there will be no beam tube, and the wiggler gap is not symmetrical in the two transverse directions [7]. The full gap in the wiggle plane is large, about $1.5 \mathrm{~cm}$, while in the plane of betatron motion the full gap varies from $0.59 \mathrm{~cm}$ at the entrance (and within the untapered section) to $0.88 \mathrm{~cm}$ at the end of the tapered section [7]. Hence, rectangular apertures with those dimensions are placed at the ends of the wiggler in the simulations. Those aper- 
tures are important sources of vignetting of the optical mode and must be taken into account in the numerical modeling of the entire system.

\subsection{Multipass simulations for a two mirror resonator.}

Our first attempts to devise an optical cavity to provide feedback of a small fraction of the amplifier's output involved a conventional, two mirror, stable resonator. In order to avoid optical damage due to very high intensity on a partially transmitting mirror which would serve as the output coupler, it was necessary to place this mirror about $2 \mathrm{~m}$ downstream of the end of the wiggler. The time required for an optical pulse to make one roundtrip in this optical cavity would equal the interval spanned by three successive electron micropulses. Simulations revealed the following situation: the optical mode at small-signal conditions diffracted into an annular mode at the outcoupler. The light reflected by the outcoupler suffered tremendous vignetting losses in passing in the upstream direction through the wiggler apertures. Further losses were incurred by reflection from the upstream mirror which must be an annular mirror in order to allow the electron beam to pass unattenuated into the wiggler entrance which is located about $10 \mathrm{~cm}$ from this mirror. Thus, although the smallsignal gain of the FEL is very large, the diffraction and vignetting losses often exceeded the gain, thus preventing the FEL from starting up. Our study of this situation produced the following conclusions: (1) for any assumed wiggler aperture dimensions and reflectivity of the upstream annular mirror (the reflectivity depends upon the hole size), the laser would always turn on for some value of the feedback from the outcoupler. However, if it took $0.1 \%$ feedback to keep the device operating in steady-state at high power, but it took $5 \%$ feedback to get the device to exceed threshold, the high power operation would lose considerable efficiency because fifty times more light than is necessary is being fed back to the wiggler entrance. (2) The calculated mode profiles at the wiggler entrance were sufficiently complicated that we did not have any faith in the accuracy of the simulation results. Thus, we could not accurately determine the required feedback to exceed threshold by simulations for a given set of wiggler apertures and hole size of the upstream mirror, although 
we were convinced that the device would work if the feedback was sufficiently large. To escape from this undesirable situation, we decided to go to a ring optical cavity.

\subsection{Results for a ring optical cavity.}

We have devised a ring-type optical cavity, shown schematically in Fig. (4), to improve the amount of light fed back to the wiggler entrance by avoiding propagation of that light through the restrictive apertures of the wiggler. A major change has been made in the outcoupler: that mirror is now an annular mirror, as is the upstream mirror. The reason is twofold: the optical mode on this mirror at small-signal conditions is also annular, so that almost all of the light is sent back along the ring (the center of the mode, which is transmitted out of the laser by the hole in the mirror, is very low intensity). At large-signal ("saturated gain") conditions, the optical mode on the outcoupler is more usual in appearance, that is, it is peaked on axis so that the annular outcoupler mirror only reflects back into the ring optics the low-intensity radial wings of the mode. Thus, almost all of the mode at small-signal is fed back by this scheme, while at large-signal the feedback is very small and most of the power is outcoupled as useful energy.

All of the results of this section are from single-wavefront simulations, and Table 2 lists some parameter values for the optical elements of the ring. The buildup of power in the cavity as a function of pass number is shown in Fig. (5); Fig. (6) shows the corresponding variation with pass number of the extraction efficiency. These two plots illustrate another phenomenon observed, but not yet fully understood, in simulations of the RAFEL device: the oscillations at steady-state, with a period of two passes, may be associated with some type of "mode beating" effect in a cavity formed with two hole-coupled mirrors. Previous studies of holecoupled resonators [8] have assumed only one of the mirrors has a central hole. When the amplitude of the oscillation is large, one sees a corresponding periodicity of the optical mode profiles. In the simulations, the oscillations can usually be tuned away by changing the inner hole radius of one of the annular mirrors, or the radii of curvature of the mirrors, or both. In the example shown, the oscillations have not been totally elimi- 
nated, but the quasi-steady-state performance is quite good: Fig. (7) shows that about $520 \mathrm{MW}$ is radiated on pass ten, and Figs. (8) - (11) show, respectively, transverse mode profiles on pass ten at the end of the wiggler, on the outcoupler, after reflection from the outcoupler, and at the wiggler entrance. The outcoupler reflects about $2.61 \%$ of the output power into the ring, but only about $0.923 \%$ of the output power is injected into the wiggler for the start of the next pass. The performance is so good, as indicated by the electron energy distribution at the end of the wiggler as shown in Fig. (12), that one could improve the extraction linearly by simply extending the length of the tapered section (keeping the same taper rate), but space limitations eliminate that possibility for the RAFEL device.

\subsection{3-D finite pulse simulations using the PARMELA electron pulse.}

The FEL simulation code FELEX [9], [10], which was used to do all of the simulation studies reported in this paper, has the ability to use directly an electron distribution generated by the linac simulation code PARMELA. We report here on the results of such a calculation which is based on the work of Sheffield [5]. Figs. (13) - (16) show, respectively, the current profile, the " $90 \%$ " emittance in the $x$-direction, the " $90 \% "$ emittance in the $y$-direction, and the variation of the energy (approximately, assuming that $\beta_{Z}=v_{Z} / c=1$ ) with axial position within the pulse. The " $90 \%$ " emittance is 4 times the rms emittance. The ragged appearance of these curves is in part due to the small number of simulation particles used in the PARMELA run and the axial zoning used in the FELEX simulation. The double-peaked current pulse arises because a sum of two Gaussian optical pulses from the drive laser are used to generate a long electron pulse from the photocathode in the PARMELA calculation. A long pulse ( $\sim 18 \mathrm{ps})$ is needed because the slippage length (neglecting corrections which arise from tapering the field in the wiggler) is about $5.47 \mathrm{ps.} \mathrm{Slippage} \mathrm{effects} \mathrm{will} \mathrm{reduce} \mathrm{the}$ FEL performance, particularly if the electron pulse is not long enough. Note that the mean electron energy varies along the pulse in a correlated manner; the energy spread at a given point, which is not shown, is less that $0.1 \%$. A wealth of details is produced by the simulation, but we will only summarize the results: as 
shown in Figs. (13) - (15) respectively, the optical power saturates at a micropulse-averaged power of about $423 \mathrm{MW}$ at the exit of the wiggler, the electron micropulse-averaged extraction efficiency saturates at about $5 \%$, and the optical pulse after ten passes is substantially shorter $(\sim 15 \mathrm{ps})$ than the electron pulse $(\sim 20 \mathrm{ps})$ due to slippage effects. However, the calculation appears to suggest that, given a more realistic electron pulse as generated by PARMELA simulations [5], the performance is reduced somewhat from the more idealized single-wavefront calculations to a level compatible with the objective of the RAFEL project, that is, a $\sim 1 \mathrm{~kW}$ average power FEL.

\section{Summary and Conclusions}

A new concept for a high-average-power FEL is being built at Los Alamos. This device, named the RAFEL (Regenerative Amplifier FEL) is a high-gain, high-extraction-efficiency FEL. It will have a compound undulator composed of $1 \mathrm{~m}$ of uniform wiggler followed by $1 \mathrm{~m}$ of linearly tapered (in field amplitude) wiggler which leads to an extraction efficiency of about $10 \%$ in idealized simulations. A ring-type optical cavity provides the optical feedback necessary for turn-on (which occurs in about five passes) and steady-state operation. The optical modes are very different from standard Gaussian modes, partly because of the high gain (small-signal and saturated) and partly because two hole-coupled mirrors are used. 4-D simulations with an electron pulse generated by a linac simulation show performance compatible with the goal of the project, namely an average power output of $\sim 1 \mathrm{~kW}$ at an optical wavelength of $\sim 16 \mu \mathrm{m}$.

\section{References}

1. G. R. Neil, S. V. Benson, H. F. Dylla, and H. Liu, Nucl. Instr. and Meth. A358 (1995) 159.

2. S. V. Benson et al., Nucl. Instr. and Meth. A375 (1996) ABS 4.

3. J. L. Adamski, D. H. Dowell, T. D. Hayward, C. G. Parazzoli, and A. M. Vetter, Nucl. Instr. and Meth. 
A375 (1996) 288.

4. R. L. Sheffield, R. H. Austin, K. C. D. Chan, S. M. Gierman, J. M. Kinross-Wright, S. H. Kong, D. C. Nguyen, S. J. Russell, and C. A. Timmer, Nucll. Instr. and Meth. A341 (1994) 371.

5. R. L. Sheffield, these proceedings.

6. Kwang-Je Kim, private communication.

7. C. M. Fortgang, these proceedings.

8. S. Krishnagopal, M. Xie, and K.-J. Kim, Nucl. Instr. and Meth. A331 (1993) 654.

9. B. D. McVey, Nucl. Instr. and Meth. A250 (1986) 449.

10. B. D. McVey, J. C. Goldstein, R. L. Tokar, C. J. Elliott, S. J. Gitomer, M. J. Schmitt, and L. E. Thode, Nucl. Instr. and Meth. A285 (1989) 186.

\section{Figure Captions.}

Figure (1) RAFEL schematic.

Figure (2) Small-signal transverse mode profiles at the end of the uniform section.

Figure (3) Small-signal transverse mode profiles at the end of the tapered section.

Figure (4) Schematic layout of optical elements of the ring cavity.

Figure (5) Power vs. pass number from single-wavefront simulation.

Figure (6) Extraction efficiency vs. pass number from single-wavefront simulation.

Figure (7) Radiated power vs. wiggler axial position on pass ten.

Figure (8) Optical transverse mode profiles at the end of the wiggler on pass ten.

Figure (9) Optical transverse mode profiles on the outcoupler on pass ten.

Figure (10) Optical transverse mode profiles after reflection by the outcoupler on pass ten.

Figure (11) Optical transverse mode profiles at the entrance of the wiggler on pass ten.

Figure (12) Electron energy distribution at the end of the wiggler on pass ten. 
Figure (13) Current profile from PARMELA.

Figure (14) 90\% emittance in x-direction from PARMELA.

Figure (15) 90\% emittance in y-direction from PARMELA.

Figure (16) Mean energy vs. axial location from PARMELA.

Figure (17) Average optical micropulse power vs. pass number from 4-D simulation.

Figure (18) Average energy extraction efficiency vs. pass number from 4-D simulation.

Figure (19) Optical pulse power vs. axial position after ten passes from 4-D simulation. 
Electron-beam parameters

Peak current

FWHM (top-hat shape)

Electron kinetic energy

Fractional energy spread

Normalized transverse emittance

Micropulse repetition rate

Macropulse duration

Macropulse repetition rate
$300 \mathrm{~A}$

$18 \mathrm{ps}$

$17 \mathrm{MeV}$

$0.1 \%$

$7.5 \mathrm{~mm}-\mathrm{mr}(\mathrm{rms})$

$108 \mathrm{Mhz}$

$20 \mu \mathrm{s}$

$60 \mathrm{hz}$

Wiggler magnet parameters

Total length

$2 \mathrm{~m}$

Wavelength

$2 \mathrm{~cm}$

Maximum field amplitude

$0.7 \mathrm{~T}$

Maximum $a_{W}$

1.3

Minimum full gap

$0.59 \mathrm{~cm}$

Untapered length

$1 \mathrm{~m}$

magnitude of linear field taper

$30.25 \%$

Modified Halbach design, 4 blocks per wavelength

Two plane focusing, equal strength in both directions

Betatron wavelength

$1.05 \mathrm{~m}$

Table 1: Electron-beam and wiggler parameters used in the simulations. 
Optical element

Outcoupler

$\begin{array}{ll}\text { Position }(\mathrm{x}, \mathrm{y}, \mathrm{z}) & (0,, 0 ., 130) \\ \text { Outer radius } & 3.0 \mathrm{~cm} \\ \text { Inner hole radius } & 0.25 \mathrm{~cm} \\ \text { Radius of curvature } & 1.0 \times 10^{10} \mathrm{~cm}\end{array}$

Mirror 2

Position

$(37.5,0 ., 130)$

Outer radius

$3.0 \mathrm{~cm}$

Inner radius

$0.0 \mathrm{~cm}$

Radius of curvature

$110.0 \mathrm{~cm}$

Mirror 3

Position

$(37.5,0 .,-109.2)$

Outer radius

$3.0 \mathrm{~cm}$

Inner radius

$0.0 \mathrm{~cm}$

Radius of curvature

$75.0 \mathrm{~cm}$

Upstream mirror

Position

$(0 ., 0 .,-109.2)$

Outer radius

$3.0 \mathrm{~cm}$

Inner hole radius

$0.25 \mathrm{~cm}$

Radius of curvature

$120.0 \mathrm{~cm}$

Table 2: Optical element parameters. The origin of coordinates is at the center of the wiggler. 


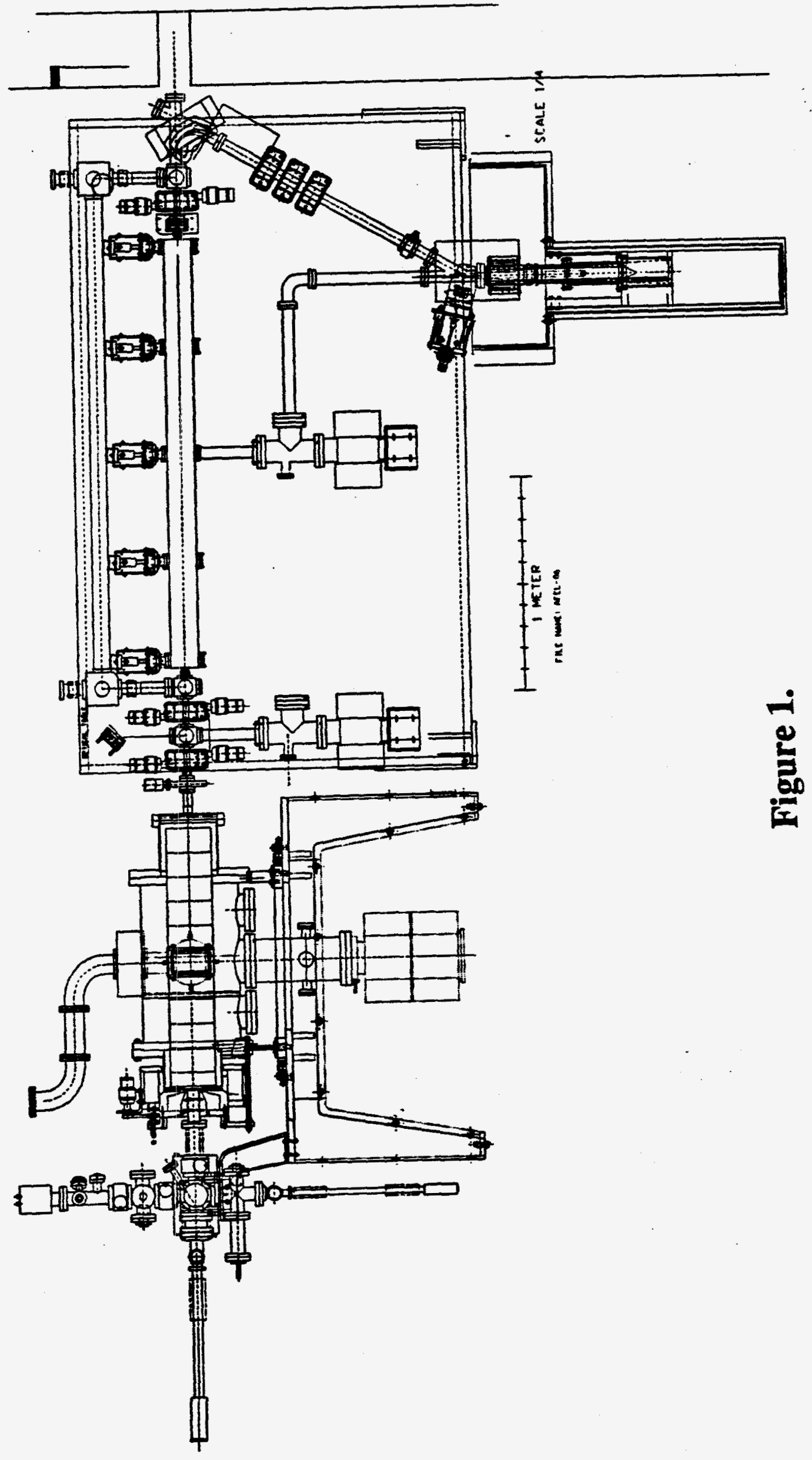




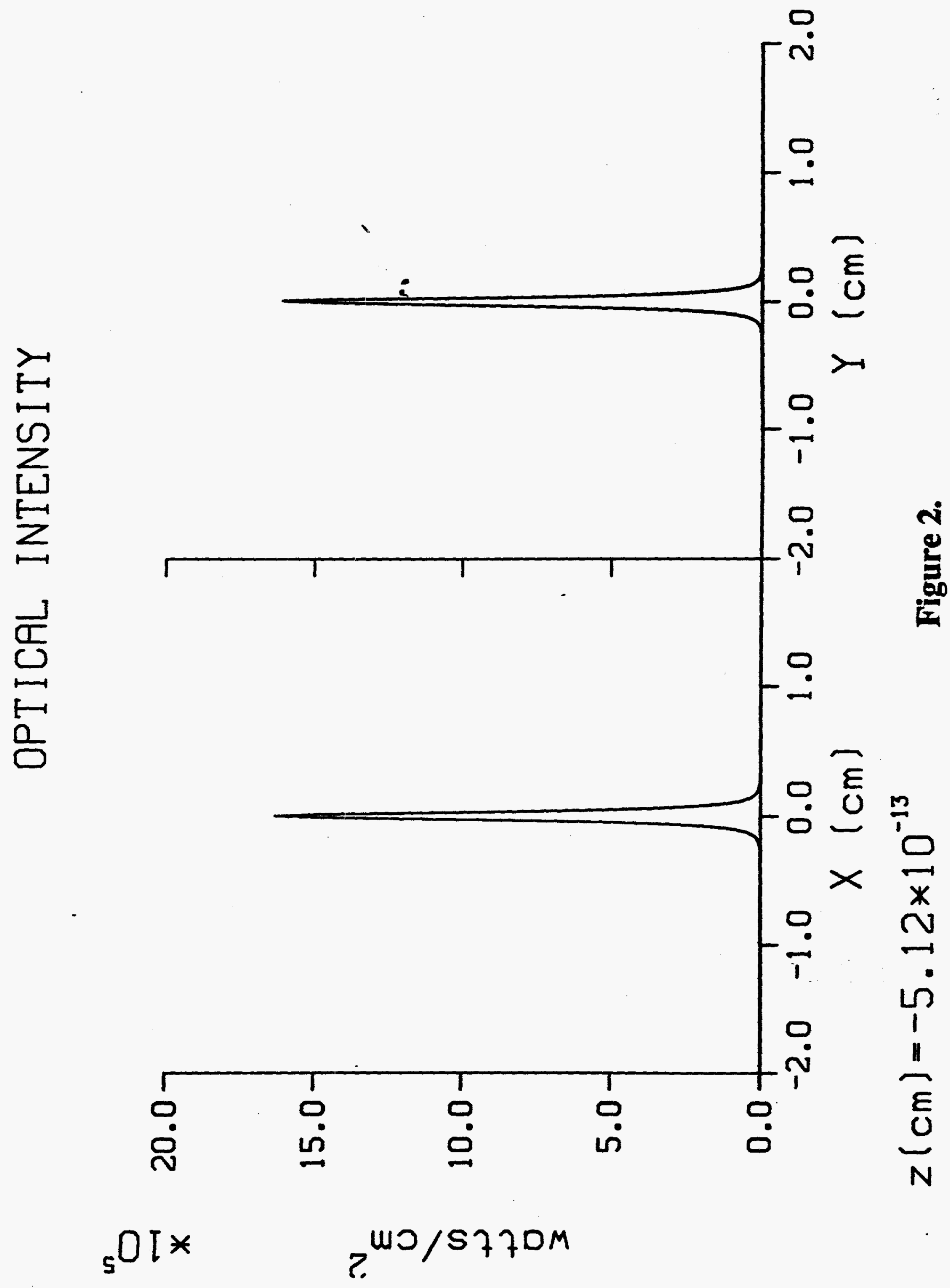




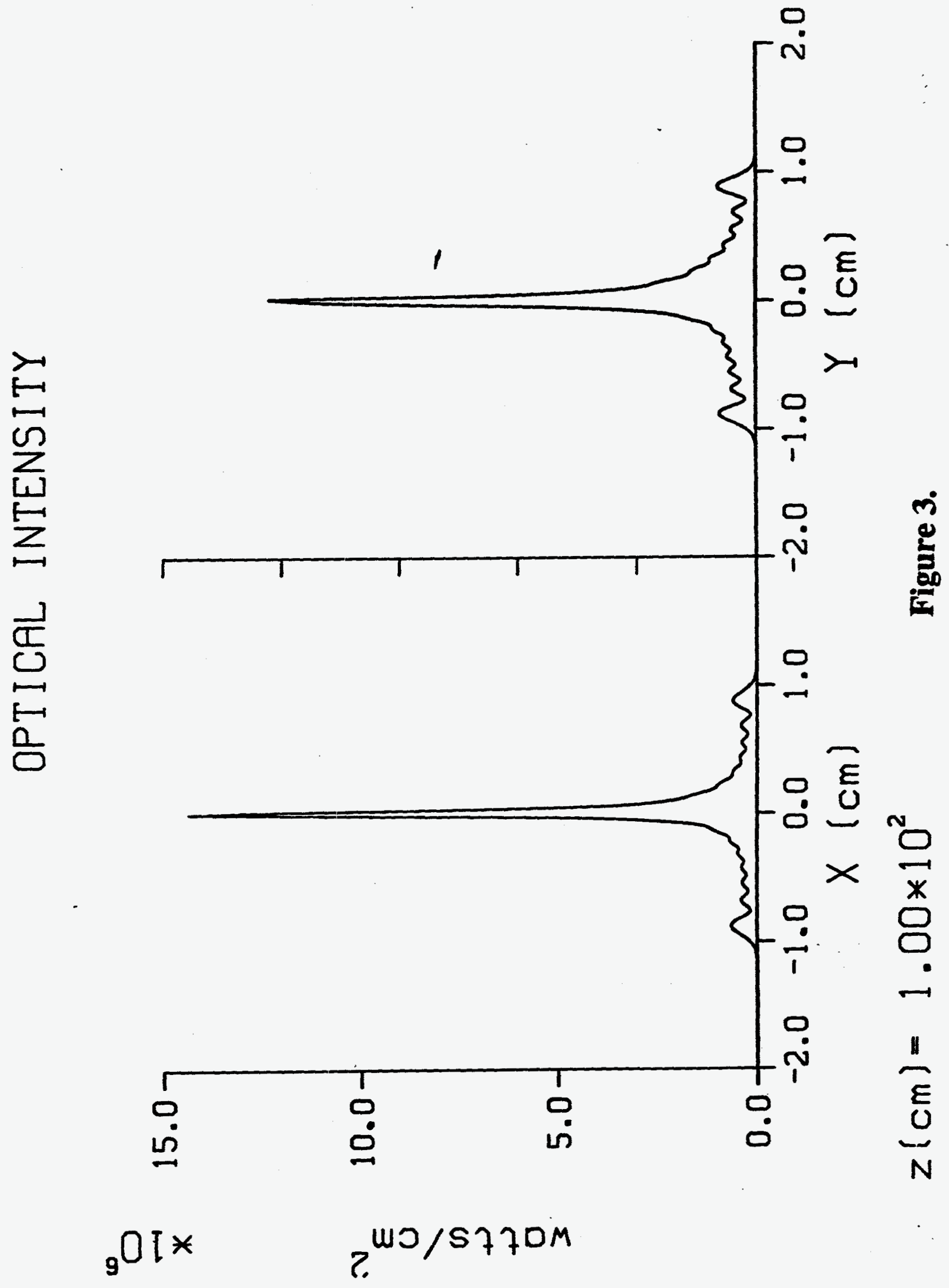




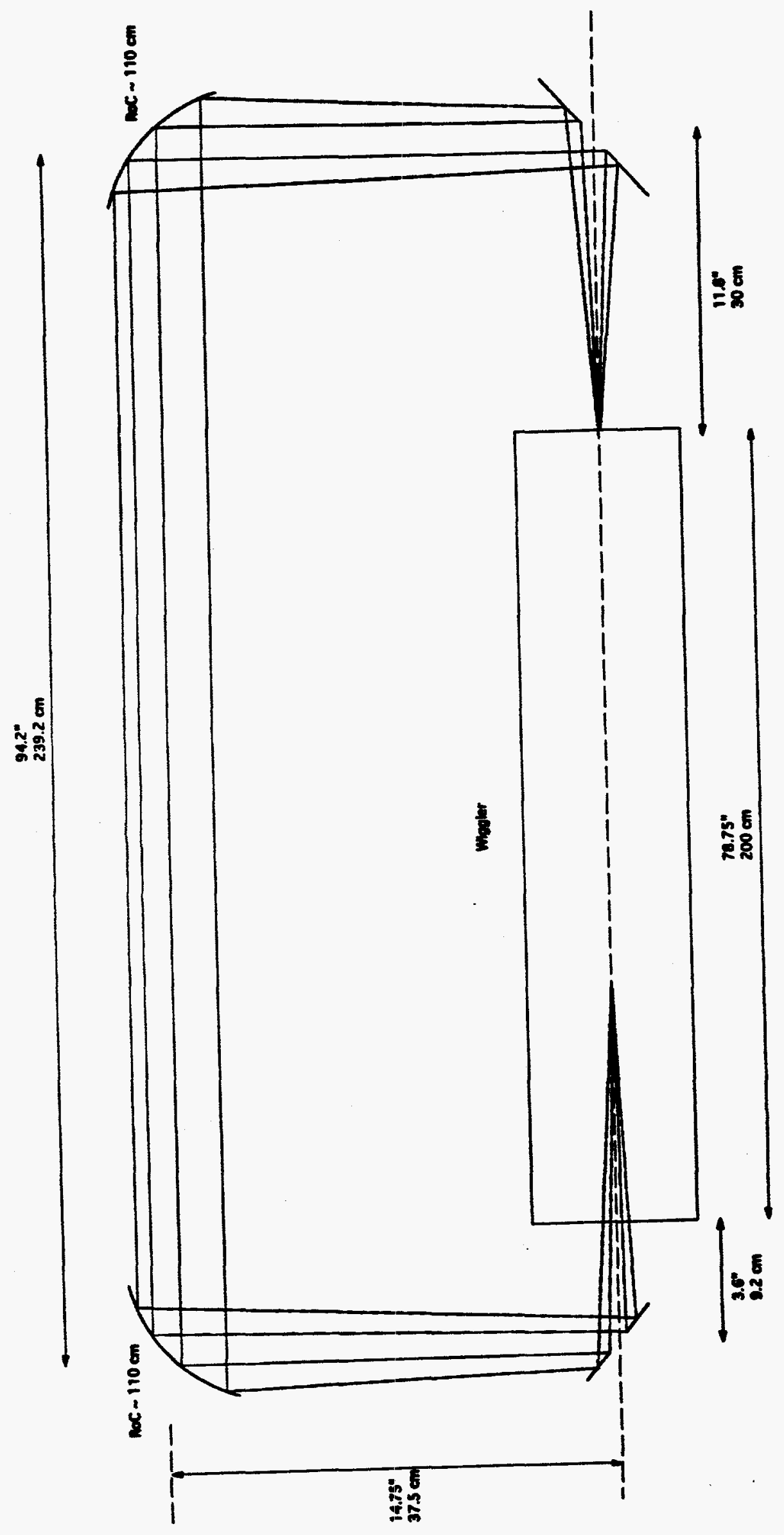

厗 


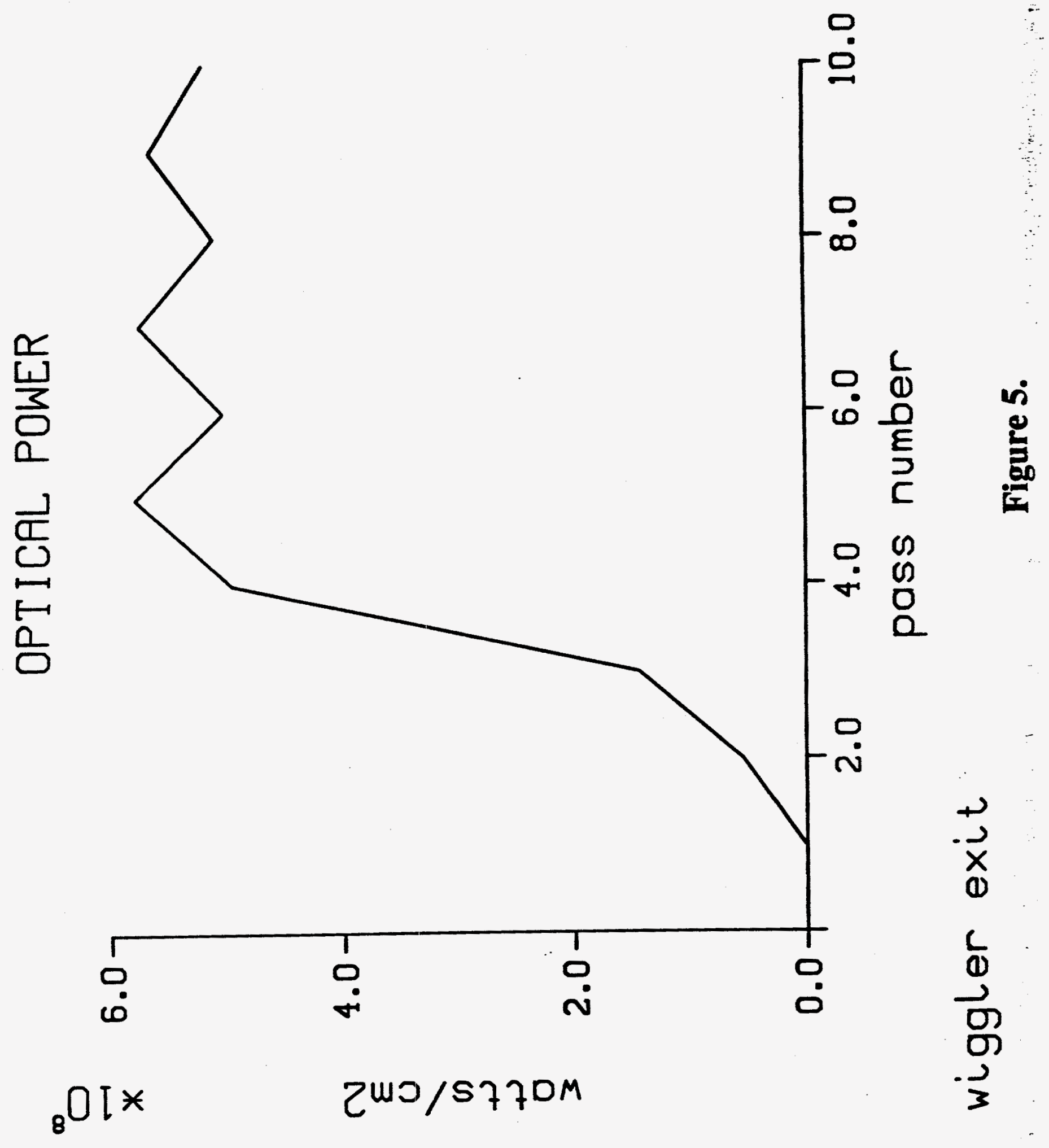




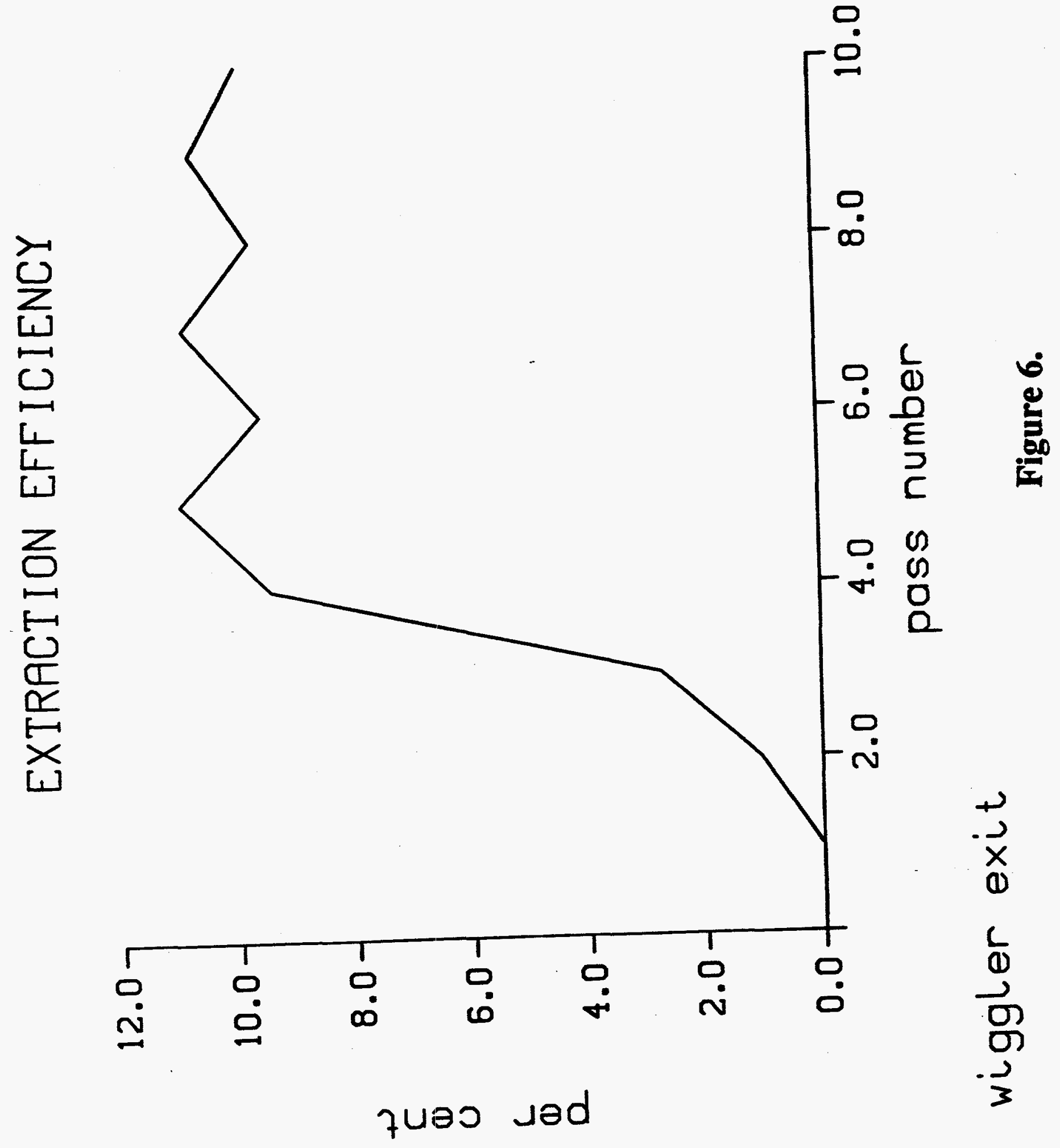


əวuน

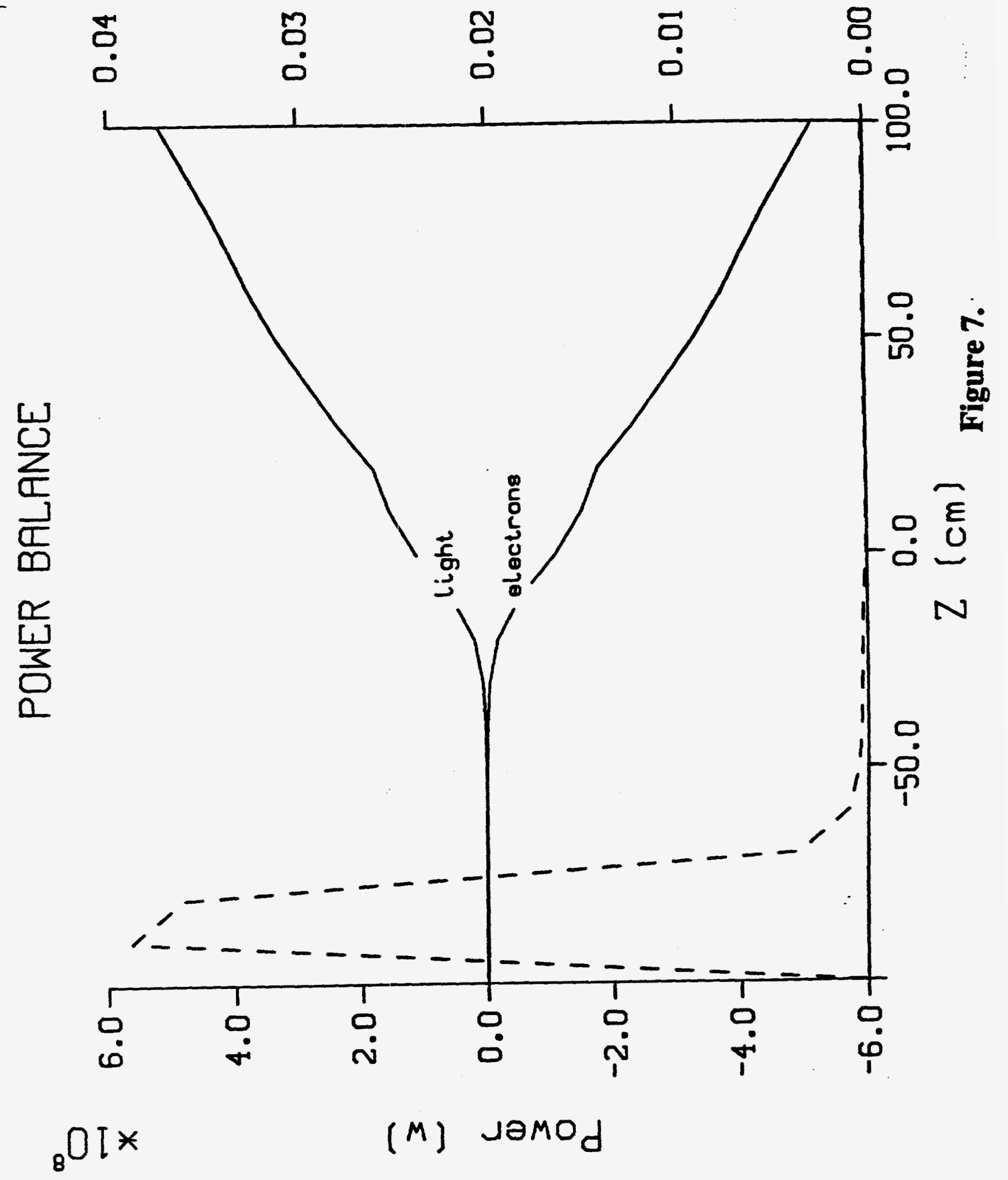




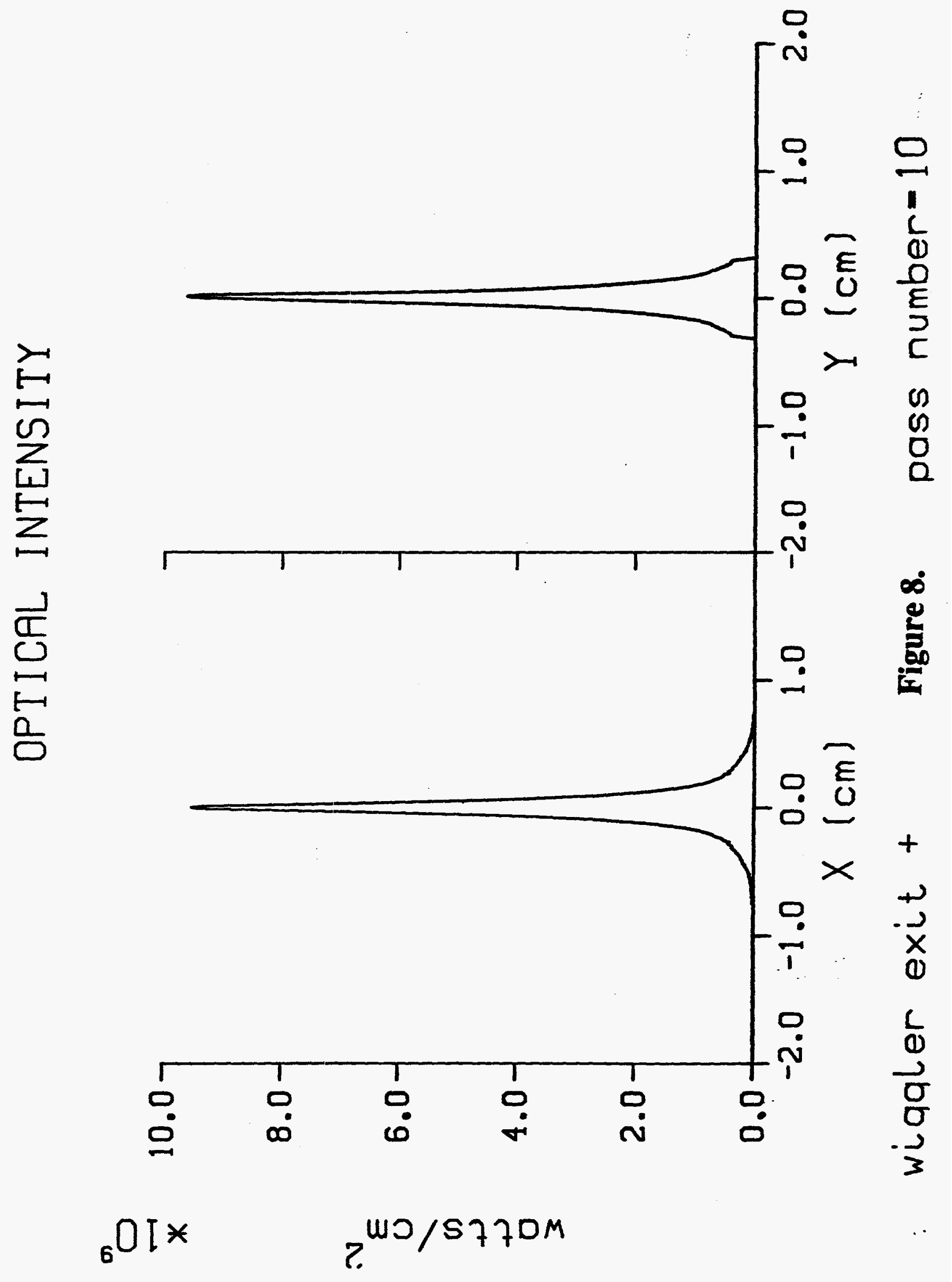




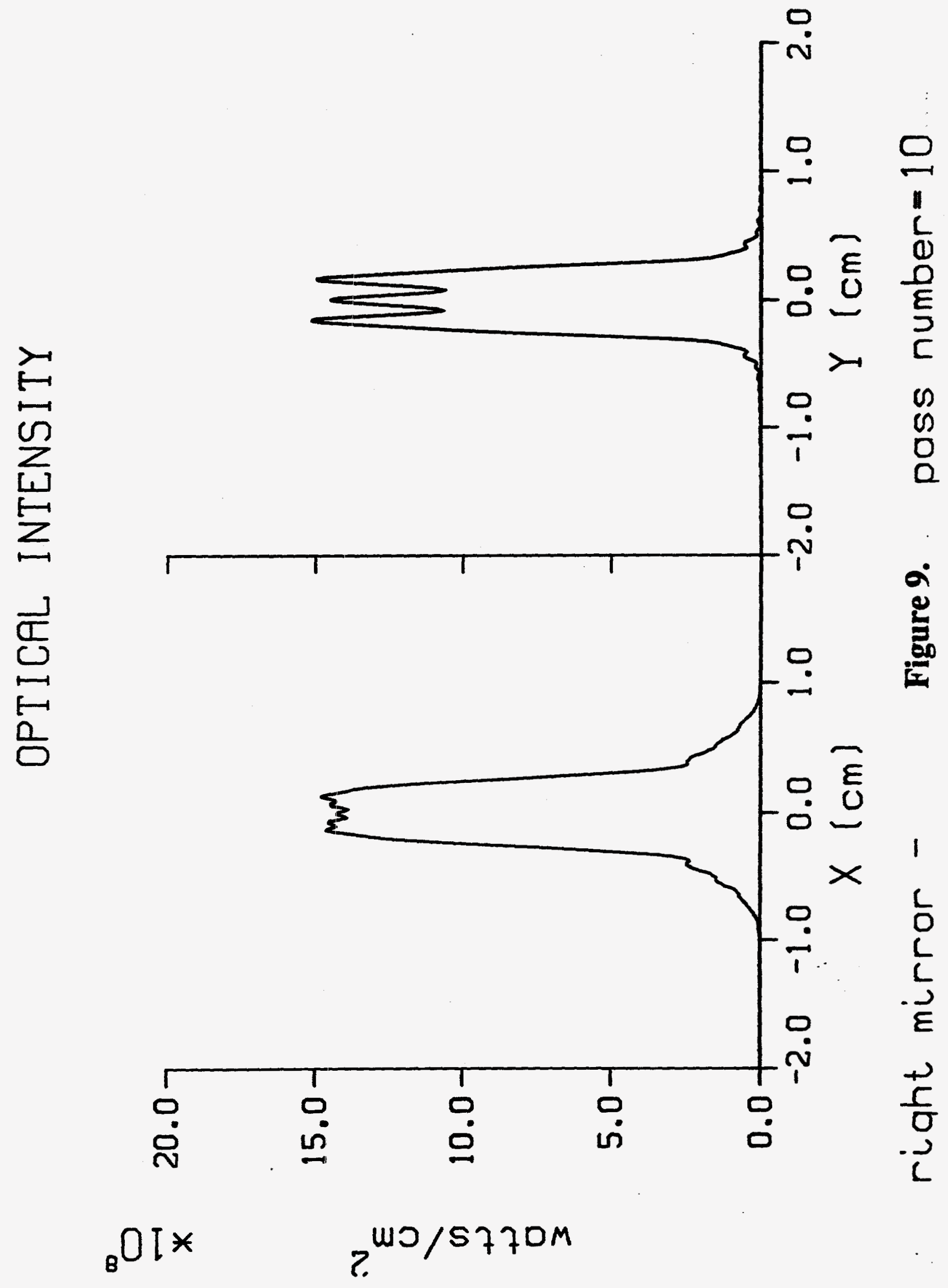




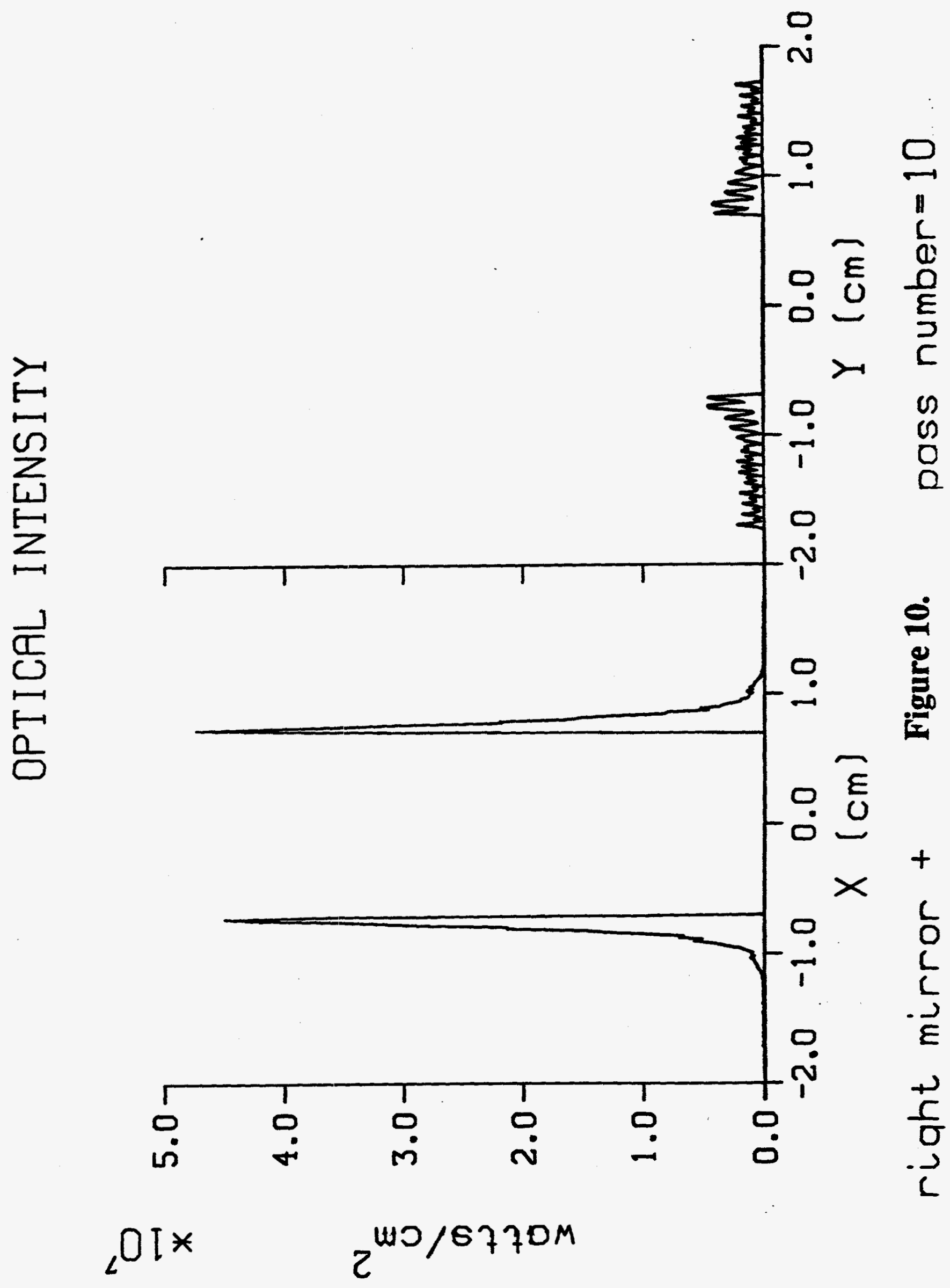




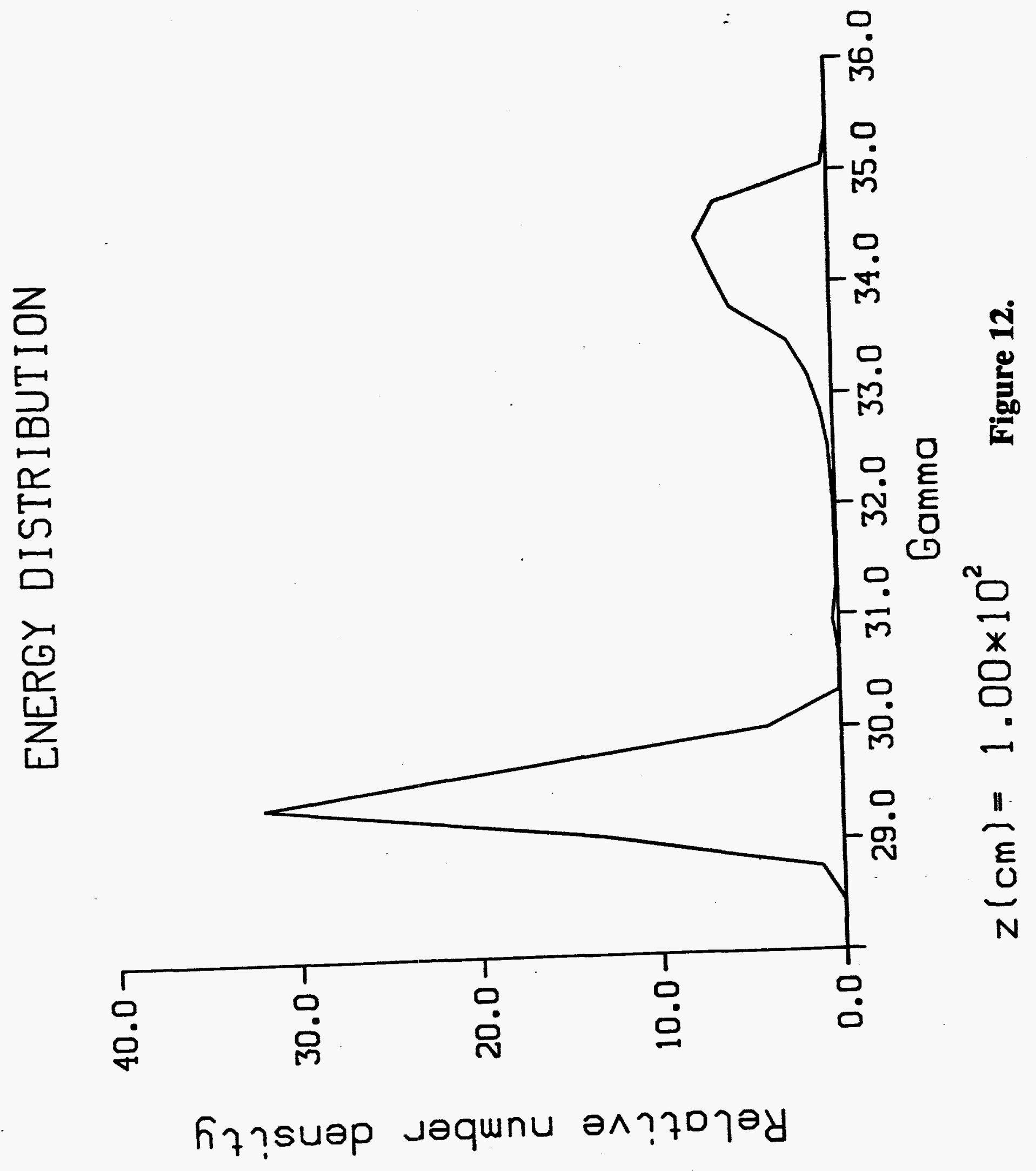




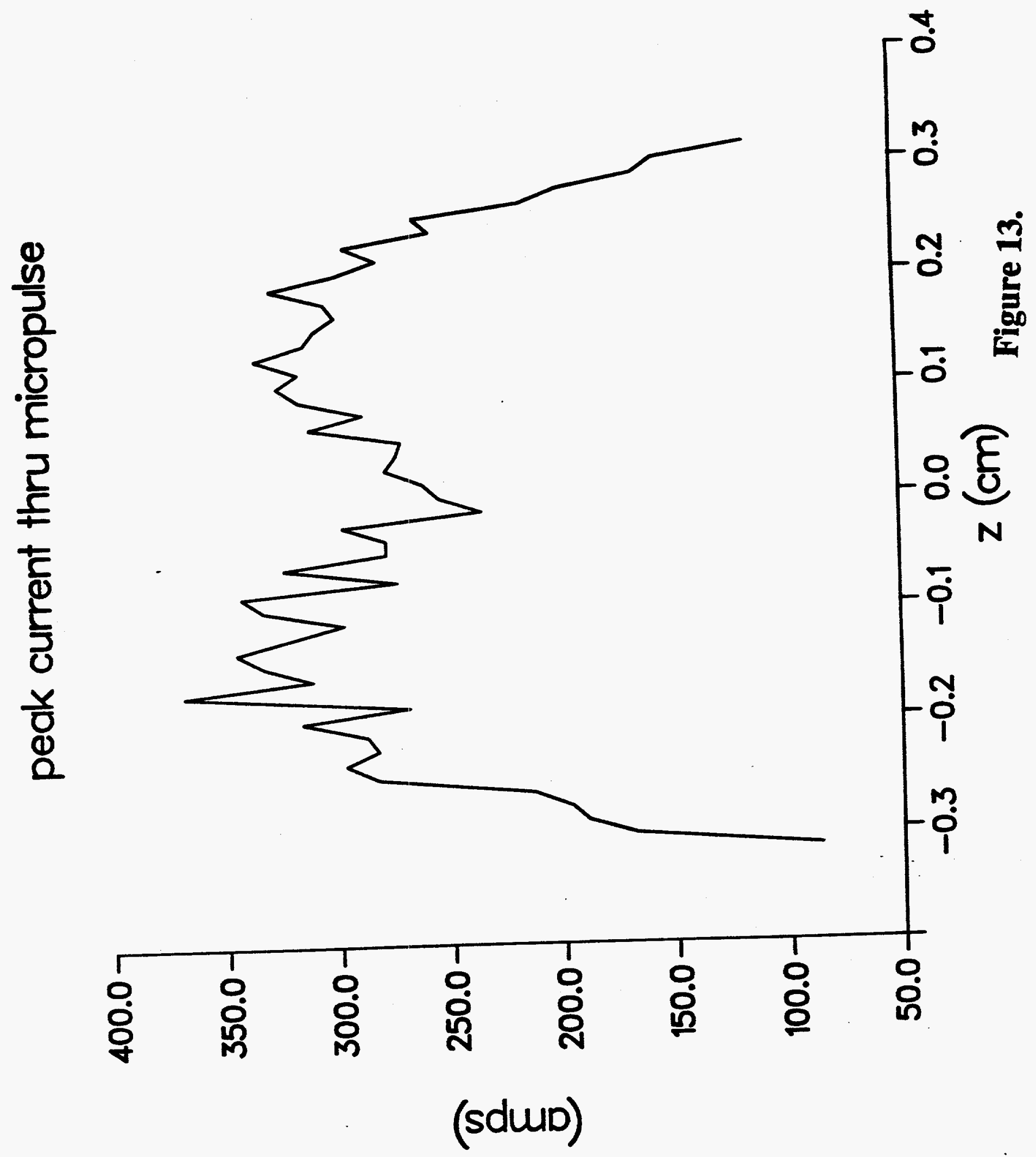




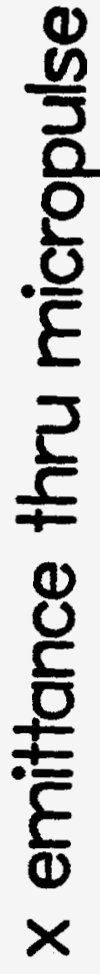

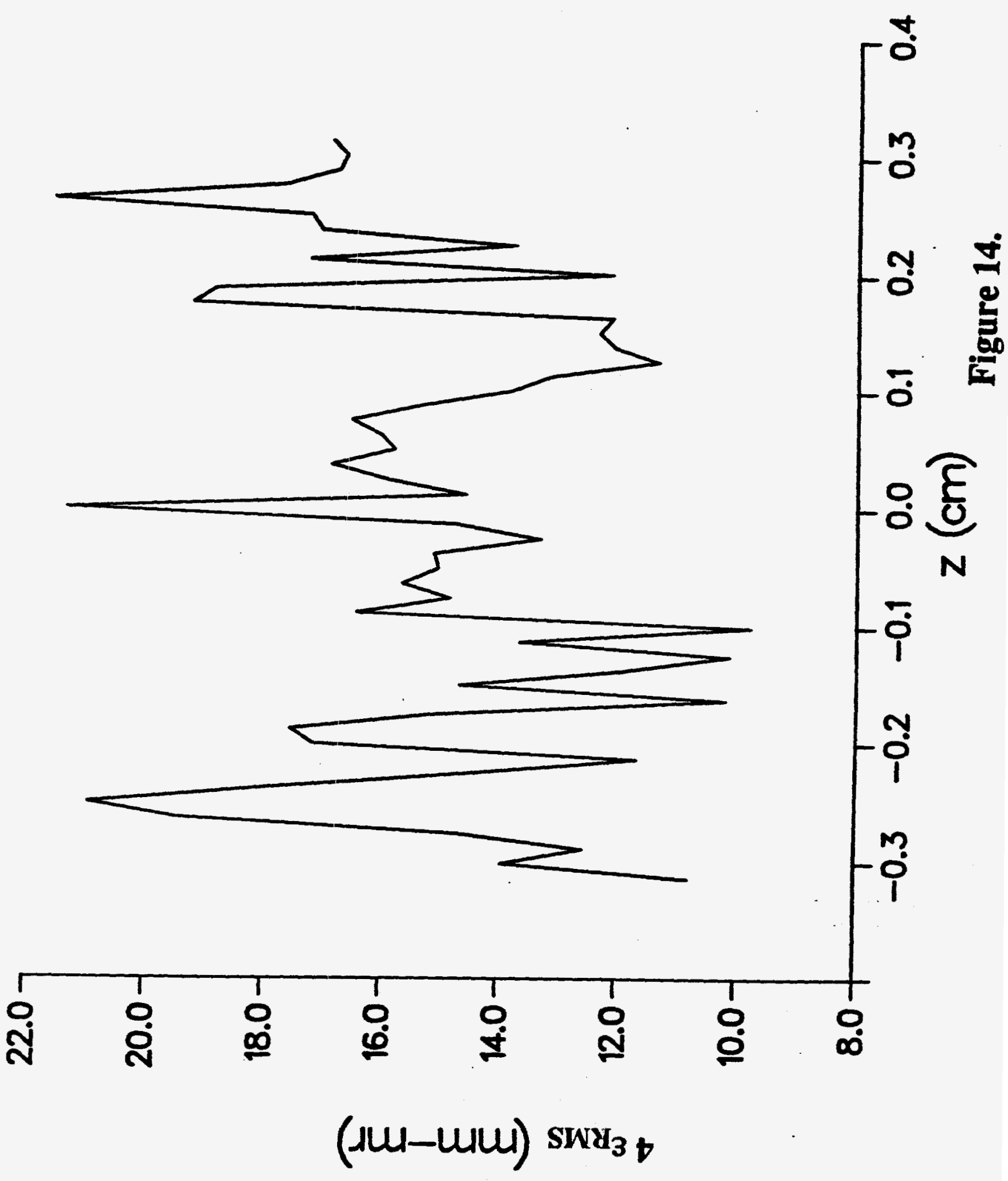




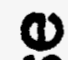

(1)

0

$\frac{0}{5}$

$\frac{0}{E}$
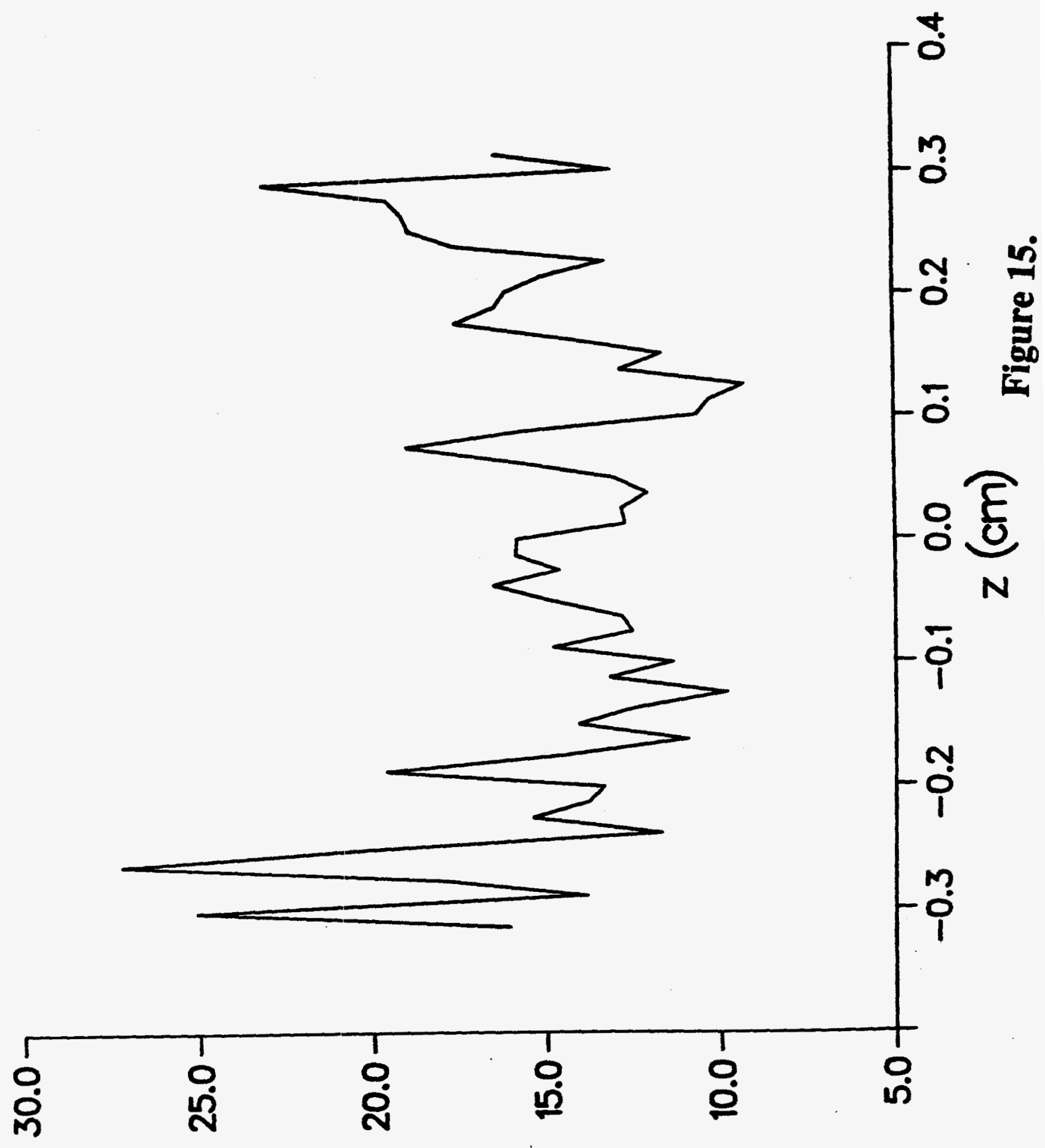

(1u-mu) sw8 


\section{average $\gamma \beta_{z}$ thru micropulse}

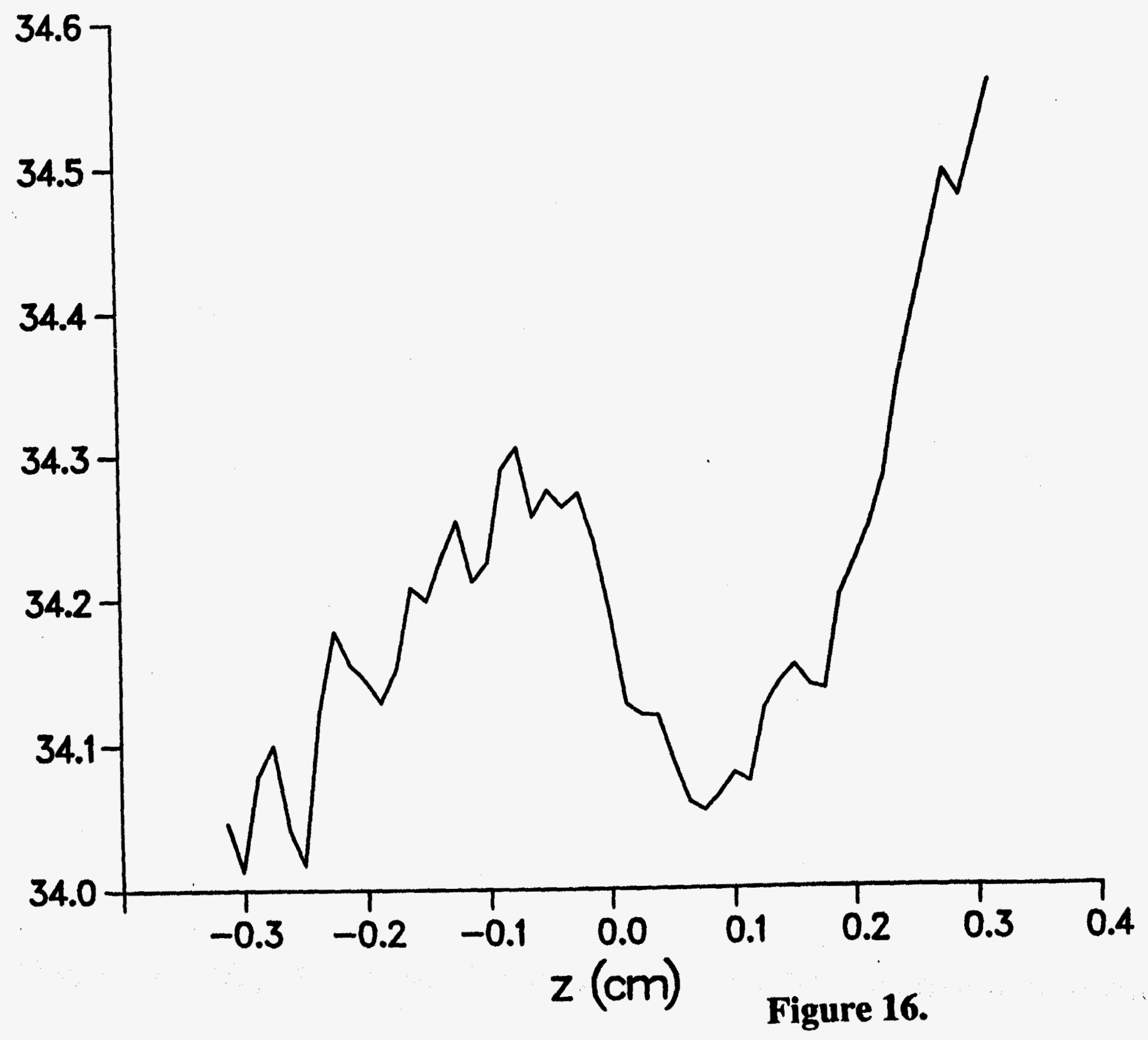




\section{average $\gamma \beta_{z}$ thru micropulse}

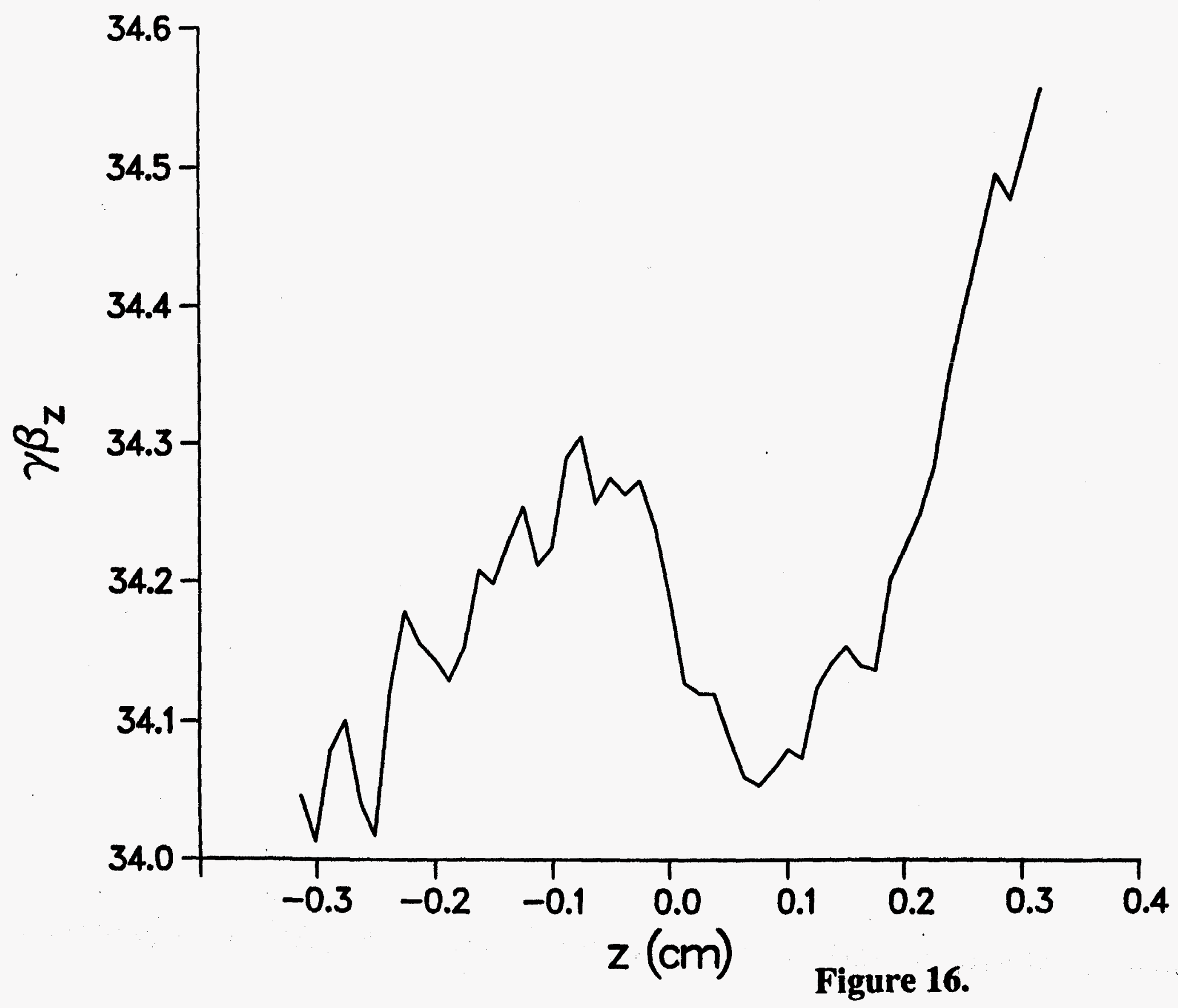




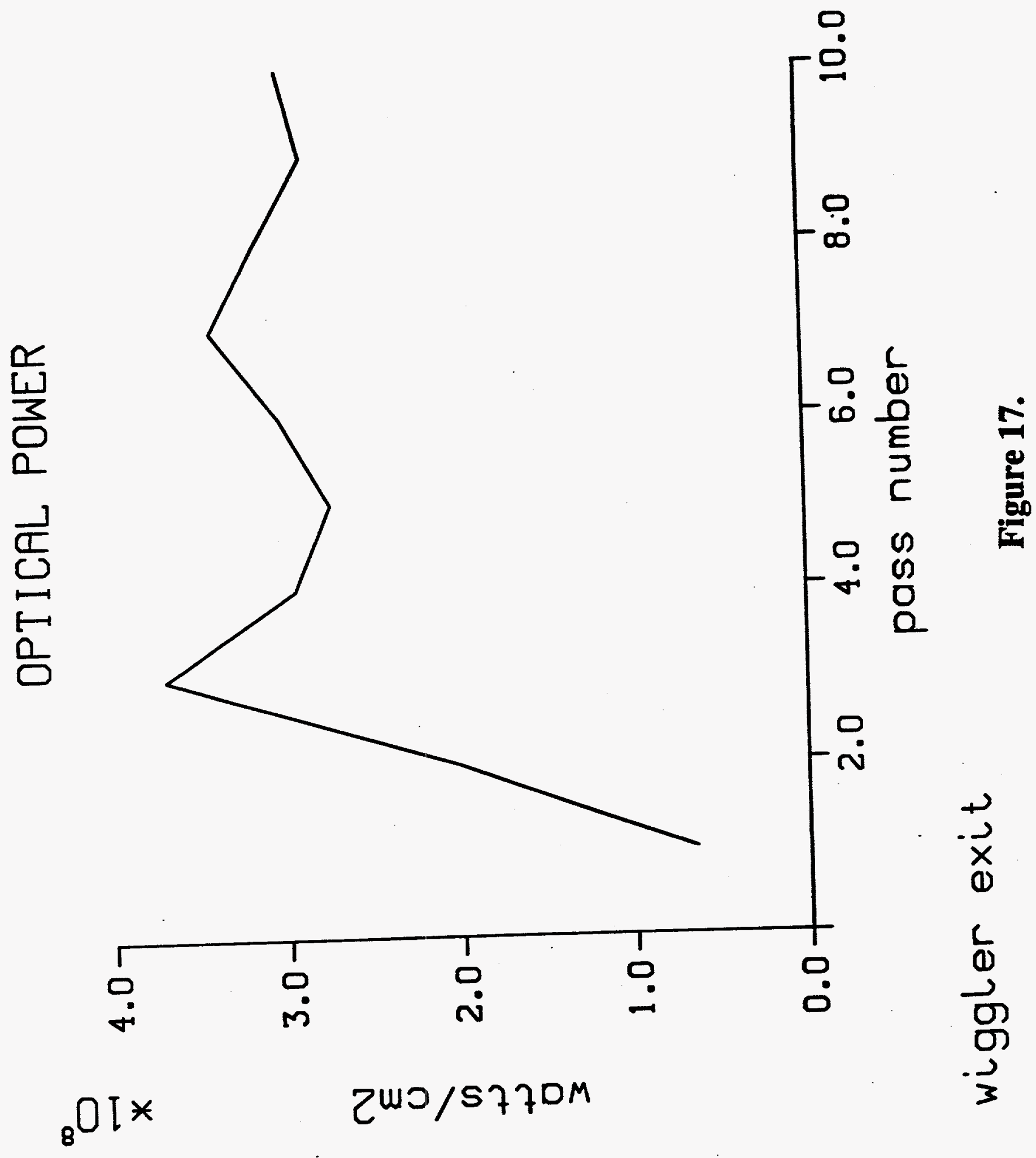




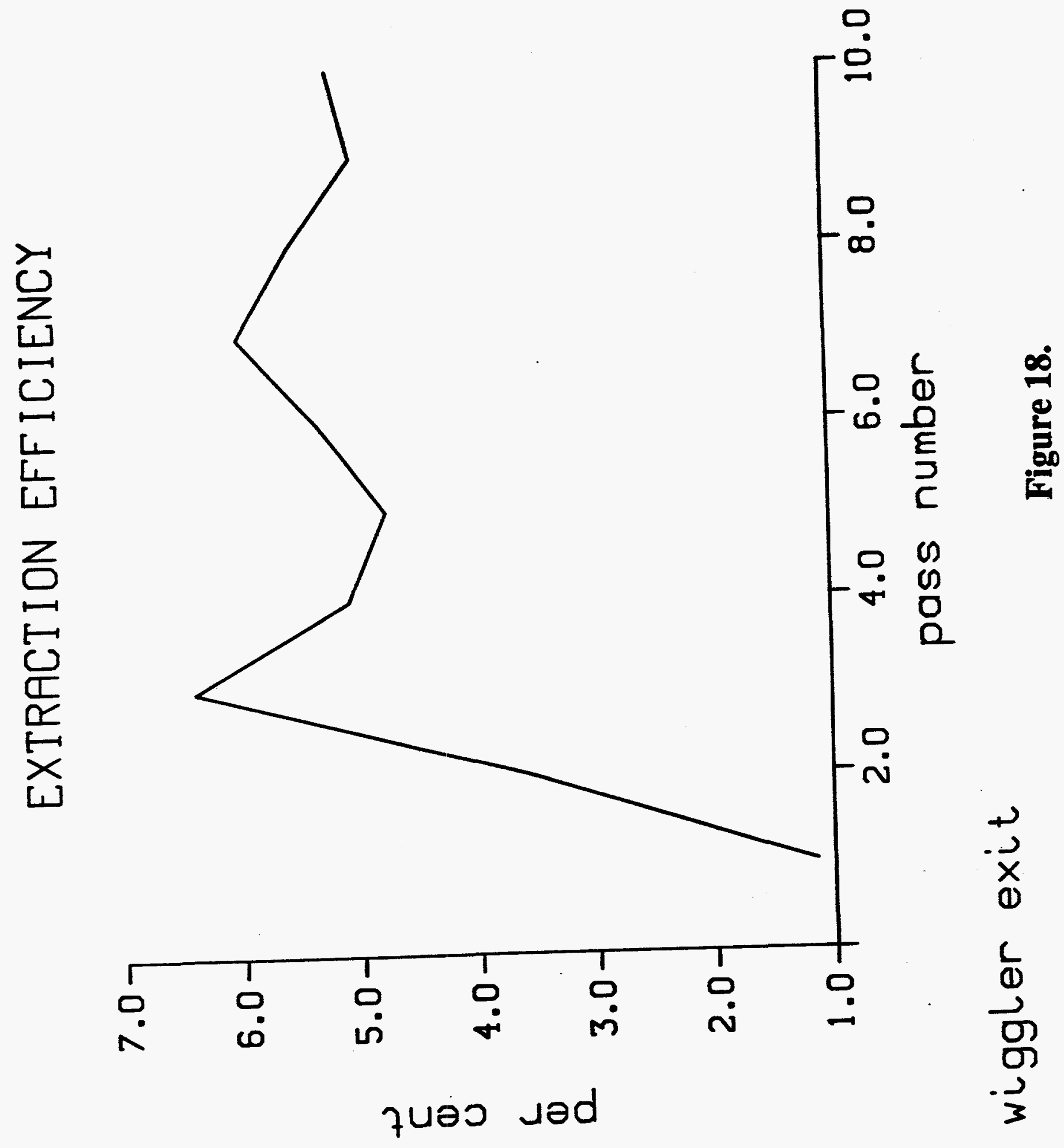


-
-

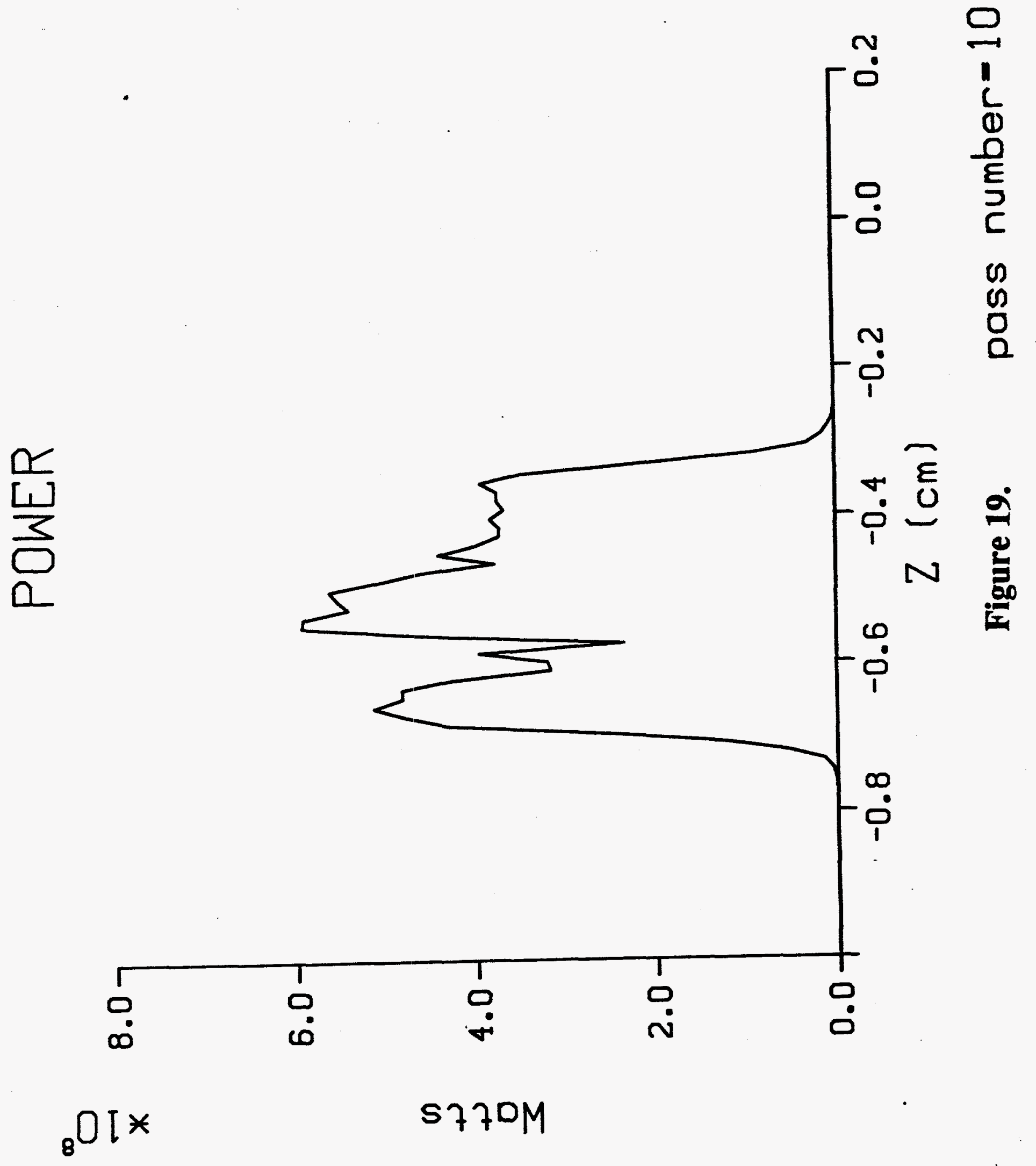




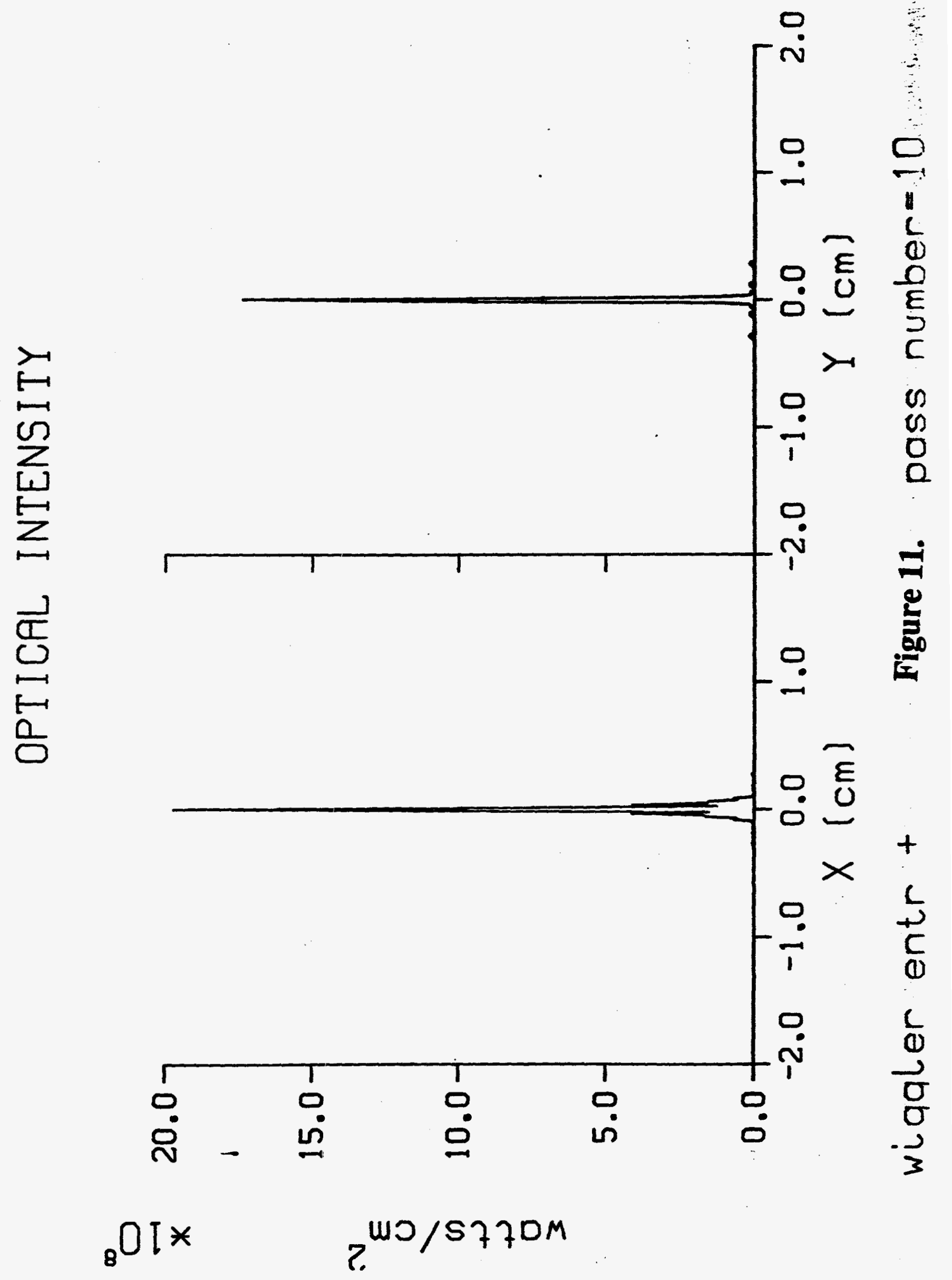

